\title{
Efficacy of Acellular-Lyophilized Human Umbilical Cord Powder Seeded with Human Umbilical Cord Mesenchymal Stem Cells in Peripheral Nerve Regeneration in Dogs Models
}

\author{
Ali A.N. AL-Zaidi ${ }^{1}$, Zeyad A. Shabeeb ${ }^{2}$, Hameed A.K. Al-Timmemi ${ }^{3}$ \\ ${ }^{1}$ Lecturer, Department of Clinics Sciences, College of Veterinary Medicine, University of Kufa, Iraq, ${ }^{2}$ Assistant \\ Professor Dr., The National Center of Hematology, Al-Mustansiriyah University, Iraq, ${ }^{3}$ Professor, Departments of \\ Surgery and Obstetrics, College of Veterinary Medicine, University of Baghdad
}

\begin{abstract}
Treatment of injuries to peripheral nerves after a segmental defect is one of the most challenging surgical problems. Therapies for peripheral nerves injury are largely ineffective. Therefore, the current study was conducted to investigate effects either acellular human umbilical cord tissue powder on repair $1 \mathrm{~cm}$ critical size defect radial nerve guided by bovine urinary bladder matrix conduit alone or seeded with mesenchymal stem cells derived from human umbilical cord. For this purpose, sixteen healthy mongrel dogs were used. They were randomly divided into two equal groups $(n=8)$, before proceeding with the surgical procedures, the dogs were generally anesthetized and aseptic conditions were established. Then, the surgery was carried out with the aid of magnifying lens. All dogs subjected to radial nerve neurotmesis from the right limb. In the scaffold group, a $1 \mathrm{~cm}$ of radial nerve was transected and resulted gap bridged with a portion of $14 \mathrm{~mm}$ acellular bovine urinary bladder submucosa conduit which was then filled with $0.05 \mathrm{mg}$ acellular human umbilical cord powder and then sutured to the two stumps using 6-0 nylon epineural by simple interrupted pattern. In combination group, the gap was bridged with acellular bovine urinary bladder submucosa conduit which was filled with $0.05 \mathrm{mg}$ acellular human umbilical cord powder then seeded with $50 \mu 1\left(5 \times 10^{6}\right)$ mesenchymal stem cells derived from human umbilical cord, then fixed onto two stumps using 6-0 nylon epineural by simple interrupted pattern. Each group was further divided into two equal subgroups $(n=4)$ categorized according to the post operation periods, that were 8 and $16^{\text {th }}$ weeks for neurohistopathological examinations. The histopathological examination of regenerated nerve sections (two samples of $5 \mathrm{~mm}$ length each) were collected from the middle (coaptation site) and distal segments were used to determine the degree of the radial nerve regeneration. The histopathological findings relative convergence between the scaffold and combination groups in their components such as the increased number of Schwann cells proliferation, parallel arrangement of nerve fibers and remarkable angiogenesis on $16^{\text {th }}$ weeks. In conclusion; this study showed that the decellularized both scaffolds alone or seeded with mesenchymal stem cells derived from human umbilical cord could support the radial nerve regeneration and allow the reinnervation of the target organ.
\end{abstract}

Keywords: Umbilical Cord, Decellularization, Mesenchymal Stem Cells, Peripheral Nerves, Dogs.

\section{Introduction}

Peripheral nerve injuries are a major medical problem in the present time and most commonly

\section{Corresponding Author:}

Ali A.N. AL-Zaidi

Lecturer, Department of Clinics Sciences, College of

Veterinary Medicine, University of Kufa, Iraq

e-mail: alizent95@yahoo.com seen in young adults. These injuries can cause loss of sensory and motor functions and lifelong disabilities ${ }^{(1)}$. In dogs the most common etiologies of nerve injuries are compression, stretching or traction, laceration, crushing and incorrect local injections of $\operatorname{drugs}^{(2)}$. Several approaches have been applied to improve regeneration, such as administration of neurotrophic factors, hormones, various biochemical substances, applications of an electric field and lasers. However, the 
clinical results were often disappointing, indicating the need for novel therapeutic approaches ${ }^{(3)}$. Cell therapy is a promising treatment strategy for promoting of repair in the injured peripheral nerves. These cells could create a more favorable environment for limiting damage and promoting regeneration via immunoregulation ${ }^{(4)}$ and combination of several features such as trophic factor production, extracellular matrix synthesis, axon guidance and sorting, remyelination, micro environmental stabilization, and immune modulation support peripheral nerve regeneration and function ${ }^{(5)}$. Various cell types have been tested for promotion of repair the injured peripheral nerves. Including, embryonic stem cells ${ }^{(6)}$, Schwann cell ${ }^{(7)}$, neural stem cells ${ }^{(8)}$ and mesenchymal stem cells ${ }^{(9)}$. In association with the development of tissue engineering, several studies have investigated the characteristics of an ideal nerve conduit in terms of its scaffolds, growth factors, and supportive cells to enhance peripheral nerves regeneration ${ }^{(10)}$.

Another approach for the peripheral nerve regeneration is biomaterials seeded with stem cells, biomaterial provides a broader platform for stem cell-based regenerative medicine ${ }^{(13)}$. The role of biomaterials serving as bioactive scaffolds to promote stem cell culture and differentiation in vitro, and providing niche for transplanting stem cell to enhance therapeutic effects ${ }^{(14)}$. (15) investigated that seeding of undifferentiated adiposederived MSCs onto decellularized nerve allografts permit the secretion of neurotrophic and angiogenic factors that can stimulate nerve regeneration. ${ }^{(16)}$ used a nerve conduit filled with a vascular bundle and bone marrow stromal cells seeded on decellularized nerve matrix in rat sciatic nerve model with a $20-\mathrm{mm}$ defect concluded that the nerve conduits constructed with vascularity, cells, and scaffolds could be an effective strategy for the treatment of peripheral nerve injuries. ${ }^{(17)}$ evaluated Laminin-chitosan-PLGA nerve guidance conduit combined with schwann and neural stem cells and showed significantly higher nerve regeneration when compared to acellular grafts in $5 \mathrm{~mm}$, laryngeal nerve defect in rat. ${ }^{(18)}$ constructed a nerve regeneration characteristics-containing nerve graft through integrating xenogeneic acellular nerve matrix seeded with autologous differentiated adiposederived mesenchymal stem cells (ADSCs) repaired $1 \mathrm{~cm}$ rat sciatic nerve defect. Therefore the aim of the study is to evaluate the efficacy of human umbilical cord mesenchymal stem cells seeded with acellular and lyophilized human umbilical cord powder guided by acellular bovine urinary bladder matrix conduit in radial nerve regeneration in dogs models.

\section{Materials and Method}

Experimental Design: Sixteen male adult local breed dogs aged (8-12) months and weighting (1520) $\mathrm{kg}$ were divided into two groups consisting of (8) animals each. In the first group, the radial nerve was transected of $(1 \mathrm{~cm})$ and the resulted gap was bridged by $(14 \mathrm{~mm})$ acellular bovine urinary bladder matrix (UBM) conduit using (0-6) nylon perineural sutures of the proximal stamp then filled intraluminally with $0.05 \mathrm{mg}$ acellular human umbilical cord (HUC) powder and then sutured to the distal stamp of the nerve, which was served as scaffold group (SG). While the second group, the gap was bridged with UBM-conduit which was filled with $0.05 \mathrm{mg}$ acellular HUC powder seeded with $50 \mu \mathrm{l}\left(5 \times 10^{6}\right)$ human umbilical cord mesenchymal stem cells (HUC-MSCs) then coaptated two stumps using 6-0 nylon epineural simple interrupted pattern and served as combination group (CG). The animals of each group were sacrificed on two periods after $8^{\text {th }}$ and $16^{\text {th }}$ weeks post operation for evaluation of histopathological examinations. All Procedures used in this study were approved by Scientific Committee, College of Veterinary Medicine, University of Baghdad-Iraq.

In Vitro Protocols: Fabrication of Conduit Derived from Bovine UBM-ECM: Fresh urinary bladders were collected as a whole from slaughtered cows at the local abattoir and the urinary bladder matrix (UBM) was prepared as a decellularized scaffold, according to method described by ${ }^{(19)}$. The urinary bladder was filled with tap water to facilitate the trimming and removing of external connective tissues and adipose tissue by scissors then washed with tap water. Tunica serosa, tunica muscularis and most of the muscularis mucosa were mechanically delaminated from the bladder tissue by scraping with the knife, and finally flattened rectangular sheet. The remaining (sub-mucosal layer) was then decellularized and disinfected by immersion the sheet in a mixture of $0.1 \%$ peracetic acid (PAA) and $4 \%$ ethanol solution on a shaker for two hours. After that, the ECM was rinsed in phosphate buffered saline (PBS) (pH 7.4) to returned the $\mathrm{pH}$ to 7.4 , containing $100 \mathrm{IU} / \mathrm{ml}$ penicillin, $100 \mu \mathrm{g} / \mathrm{ml}$ streptomycin and 100 $\mu \mathrm{g} / \mathrm{ml}$ amphotericin $\mathrm{B}$ at $25{ }^{\circ} \mathrm{C}$ with shaking, then in two changes deionized water and finally one change of PBS, 15 min each. The decellularized ECM scaffolds were sterilized by immersion in $0.1 \%$ PAA solution for 
five hours ${ }^{(20)}$. Finally the disinfected and decellularized sheets were cut at certain sizes and used for wrapping the UBM around the stainless steel pin at different sizes depending on the diameter of the tube (wall thickness of $0.18 \mathrm{~mm}$, and a length of $\mathrm{I} 4 \mathrm{~mm}$ ). Then, they were adhered to the two edges of the tube by using biological adhesive.

Fabrication of Powder Derived from HUC-ECM: The human umbilical cord tissue powder was obtained as described by ${ }^{(21)}$. About $20-25 \mathrm{~cm}$ of umbilical cord tissue was collected in phosphate-buffered saline (PBS) (Sigma, USA) and transported to the laboratory. UCs were washed with PBS under a sterile laminar flow cell culture hood and cut into $5 \mathrm{~cm}$ segments. The segments were cut longitudinally, and blood vessels were removed, and then transferred in $50 \mathrm{ml}$ conical tube to freeze $(24 \mathrm{~h}$ at $-20 \mathrm{C}^{\circ}$ ), aseptically transported into the laboratory, and subsequently thawed and transversely cut into pieces $(\sim 0.5 \mathrm{~cm}$ length). Tissue pieces were agitated in $0.1 \mathrm{M}$ phosphate-buffered saline bath $\left(48 \mathrm{~h}\right.$ at $\left.4 \mathrm{C}^{\circ}\right)$. The PBS bath was exchanged three times before the tissue pieces were soaked in $0.02 \%$ trypsin/ $0.05 \%$ EDTA (120 min. with shaking) and afterward in $0.1 \%$ peracetic acid in $4.0 \%$ ethanol bath (120 min. with shaking), and then socked in a series of PBS and deionized water $(\mathrm{dH} 2 \mathrm{O})$ for $15 \mathrm{~min}$ two times of each. The decellularized HUCECM was allowed to set slightly before being transferred to $-20^{\circ} \mathrm{C}$ for 24 hours then transferred to the deep freezer at $-80^{\circ} \mathrm{C}$ for 5 days. The tissue was subsequently lyophilized for 24 hours at $-56^{\circ} \mathrm{C}$ under $5 \mathrm{~mm} \mathrm{Hg}$ in a lyophilizer for lyophilization till it was completely dried. The samples were then grinded with mixer mill device.

Isolation and culturing of HUC-MSCs by Explant-Enzymatic Method: Human umbilical cords (HUCs) were obtained from women with healthy pregnancies during caesarean deliveries at the end of gestation after signing informed consents. UCs collected under sterile conditions and transported to the laboratory in Dulbecco's Modified Eagle's Medium (DMEM) (Gibco. USA), 10U/ml penicillin G, $10 \mathrm{U} /$ $\mathrm{ml}$ streptomycin, $25 \mathrm{mg} / \mathrm{ml}$ amphotericin B (Gibco. USA). MSCs were isolated and cultivated according to protocol described by ${ }^{(22)}$; briefly, about $10-15-\mathrm{cm}$ of HUC was transferred to a biosafety cabinet II and was washed several times with sterilized PBS to remove traces of blood, then immersed in $70 \%$ ethanol for 30 second and then immediately washed in PBS. The tissue then placed in a $10-\mathrm{cm}$ sterilized petri dish and was divided into $5-\mathrm{cm}$ pieces and longitudinally cut each piece and the blood vessels were removed from each piece. Each piece then minced into small pieces $(\sim 2-3$ $\mathrm{mm}^{3}$ ) and washed with PBS.Explants were then placed in $50 \mathrm{ml}$ falcon tube containing a solution of $1 \mathrm{mg} / \mathrm{ml}$ Collagenase I (Gibco USA) in low glucose DMEM (Gibco USA) which were then incubated for $1 \mathrm{~h}$ at $37^{\circ}$ $\mathrm{c}$ in a humidified atmosphere containing $5 \% \mathrm{CO}_{2}$, the explants pieces then were washed with PBS solution and 6 - 9 pieces were transferred onto tissue culture $75-\mathrm{cm} 2$ T-flasks and were left undisturbed for 3 - 5 minutes until attachment onto flask. Then, complete culture medium was added. For the digested suspension was diluted 1:2 with PBS solution and centrifuged at $80 \mathrm{~g}$ for 10 min at cool centrifuge $4 C^{\circ}$. Supernatant discarded and cell pellets resuspended in complete culture medium in tissue culture $75-\mathrm{cm} 2$ T-flasks. The culture flasks were left undisturbed for 3 - 4 days and maintained at $37^{\circ} \mathrm{C}$ in a humidified atmosphere $90 \%$ containing $5 \%$ $\mathrm{CO} 2$ for 3 days. Non-adherent cells were removed and fresh medium was replaced from 3 to 12 days After 12 days when the culture reached confluence at passage zero (P0), monolayer cell cultures were subculture for collecting homogenous stromal stem cells. The number of cells in each culture flask was quantified using a haemocytometer. The total number of cells harvested from the tissue culture flasks was determined by using the following equation ( $\left.\mathrm{NCxDx} 10^{4} / \mathrm{HQ}\right) \mathrm{NC}=$ number of count vital cells (non-vital cells were stained blue), $\mathrm{D}=$ sample dilution $(10)$ and $\mathrm{Q}=$ number of squares used haemocytometer ${ }^{(23)}$.

Immunocytochemistry Analysis of HUC-MSCs: At the second passage, the fibroblast-like cells became morphologically homogeneous, the following $\mathrm{CD}$ markers were used (primary antibodies) for detection of MSCs (anti- dog CD90) and (anti- dog CD 34). The procedure of immunocytochemistery of MSCs was applied according to the manufacture instruction of (Santa Cruz biotechnology Company).

Modified Surgical Procedure: Dogs were premedicated with atropine sulfate in dose rate of 0.03 $\mathrm{mg} / \mathrm{kg}$, then after 10 minutes the dog was anaesthetized by a mixture of $5 \mathrm{mg} / \mathrm{kg}$ of Xylazine hydrochloride) and $15 \mathrm{mg} / \mathrm{kg}$ Ketamine hydrochloride I/M respectively. The skin was disinfected with chlorhexidine gluconate, Isopropyl alcohol $70 \%$ and finally with $1.8 \%$ tincture iodine. The paw was extended by placing a latex glove over the distal extremity and securing it to the limb with a tape. The glove was covered with sterile skin towel and secured to the limb with towel clips. Then, the animal 
was placed on left lateral recumbency and an aperture of fenestrated drape was made on the right forelimb at the targeted operation area. The proximal and central humeral diaphysis were used as landmarks through a craniolateral approach. Skin incision about $(5-7 \mathrm{~cm})$ from the cranial border of the tubercle of the humerus and distally to the middle level of the humerus and the incision follow the normal curvature of the humerus was made. The subcutaneous fat and brachial fascia was incised along the same line; the cephalic vein was protected and isolated. The brachial fascia along the border of the brachiocephalicus muscle and lateral head of the triceps was incised bluntly to avoid rupture of the radial nerve and by aid of gelpi retractor; the lateral head of triceps brachialis and brachiocephalicus muscles were retracted to expose the nerve. Caution was used when incising the fascia along the cranial border of the triceps overlying the brachialis muscle until the radial nerve is visualized. After the radial nerve was exposed, the nerve was severed proximally by using sterile scalpel blade size (No. 10) and then distally transected the $1 \mathrm{~cm}$ segment mid portion of the right radial nerve. In the scaffold group (SG), the single 6-0 nylon suture was employed in an epineurial grasping stitch pattern to fix the proximal stump of the nerve into the conduit. Then, the conduit was filled with $0.05 \mathrm{mg}$ acellular and lyophilized human umbilical cord scaffold. While in the combination group (CG), it was treated by implantation of the same conduit which was filled with $0.05 \mathrm{mg}$ acellular human umbilical cord tissue ECM scaffold seeded with HUCMSC $50 \mu 1$ $\left(5 \times 10^{6}\right)$. Then the distal end was also sutured in the same way as the proximal end. Finally, the brachiocephalicus muscle and the superficial pectoral muscles were sutured to the fascia of the brachialis muscle with 3-0 Polydioxanone simple continuous sutures. Suture the subcutaneous tissue and skin with standard method.

\section{Results}

Neurohistopathology: Histopathological examination of the mid-segment of the radial nerve in the scaffold group (SG), on $8^{\text {th }}$ weeks PO showed moderate number of Schwann cells, undulation arrangements of regenerative nerve fibers and improved angiogenesis (Fig. 1A). The distal segment showed presence of thick eosinophilic remyelination sheaths with new regenerated nerve fibers at the site of nerve transection surrounded by polymorphonuclear inflammatory cells (Fig. 1B).

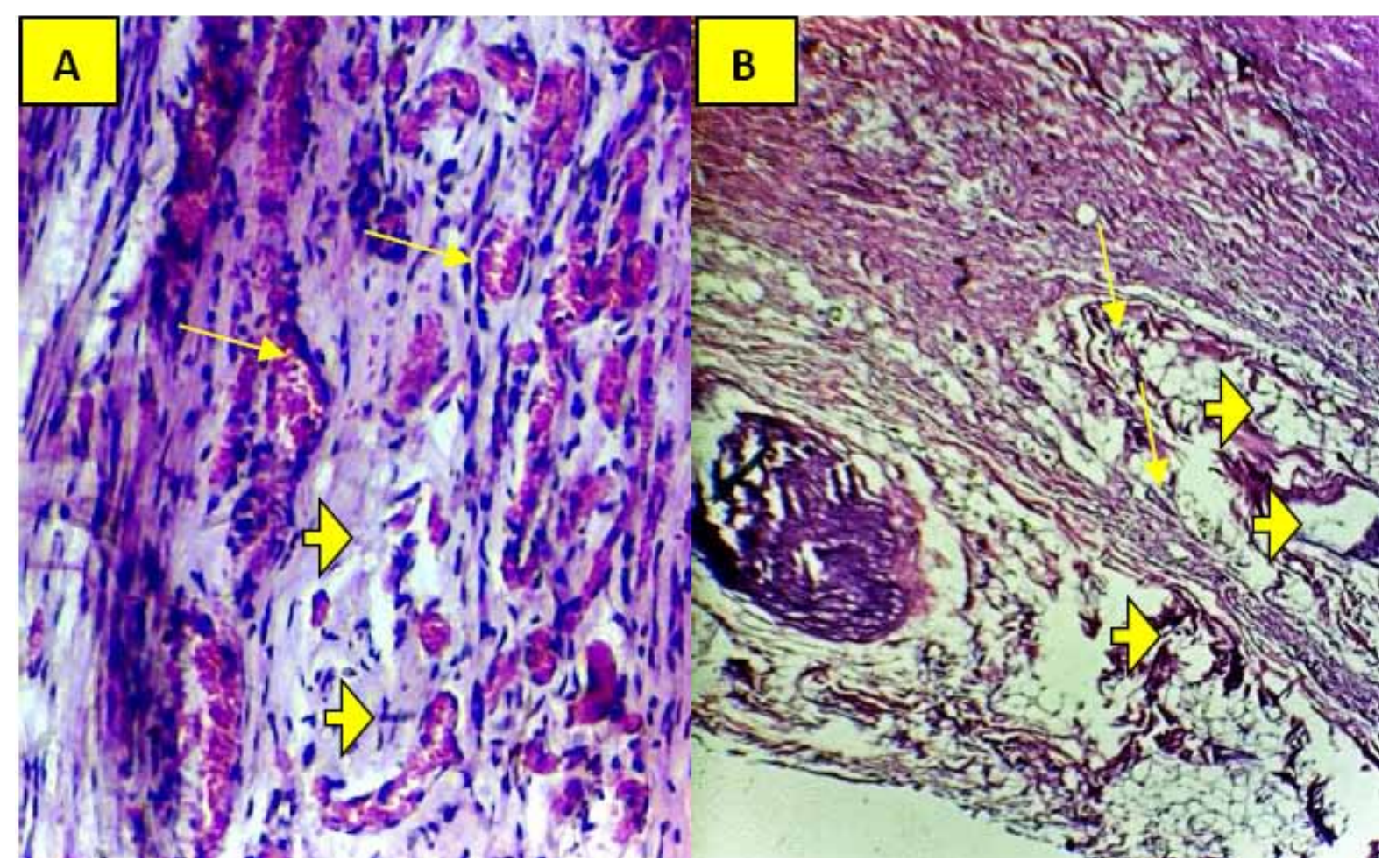

Fig. 1: Longitudinal section of the radial nerve in (SG)at 8th weeks PO. A. middle segmentshows undulation arrangements of regenerative nerve fibers with few degenerated nerve fibers (head arrow), and improved angiogenesis (thin arrows).B. distal segment shows new regenerated nerve fibers at the site of nerve transection (thin arrows) surrounded by polymorphonuclear inflammatory cells (head arrows). H \& E X 20 
Histopathological examination of middle section in scaffold group at 16 weeks PO showed minimum vacuolated degenerated nerve fibers, improved myelination and increased number of schwann cells (Fig. 2A). The distal segment, there were a higher number of basophilic nerve fibers, rich in schwann cells with apparently slight derangement of the architecture of nerve fibers (slight undulation) with few remnant of conduit (Fig 2B).

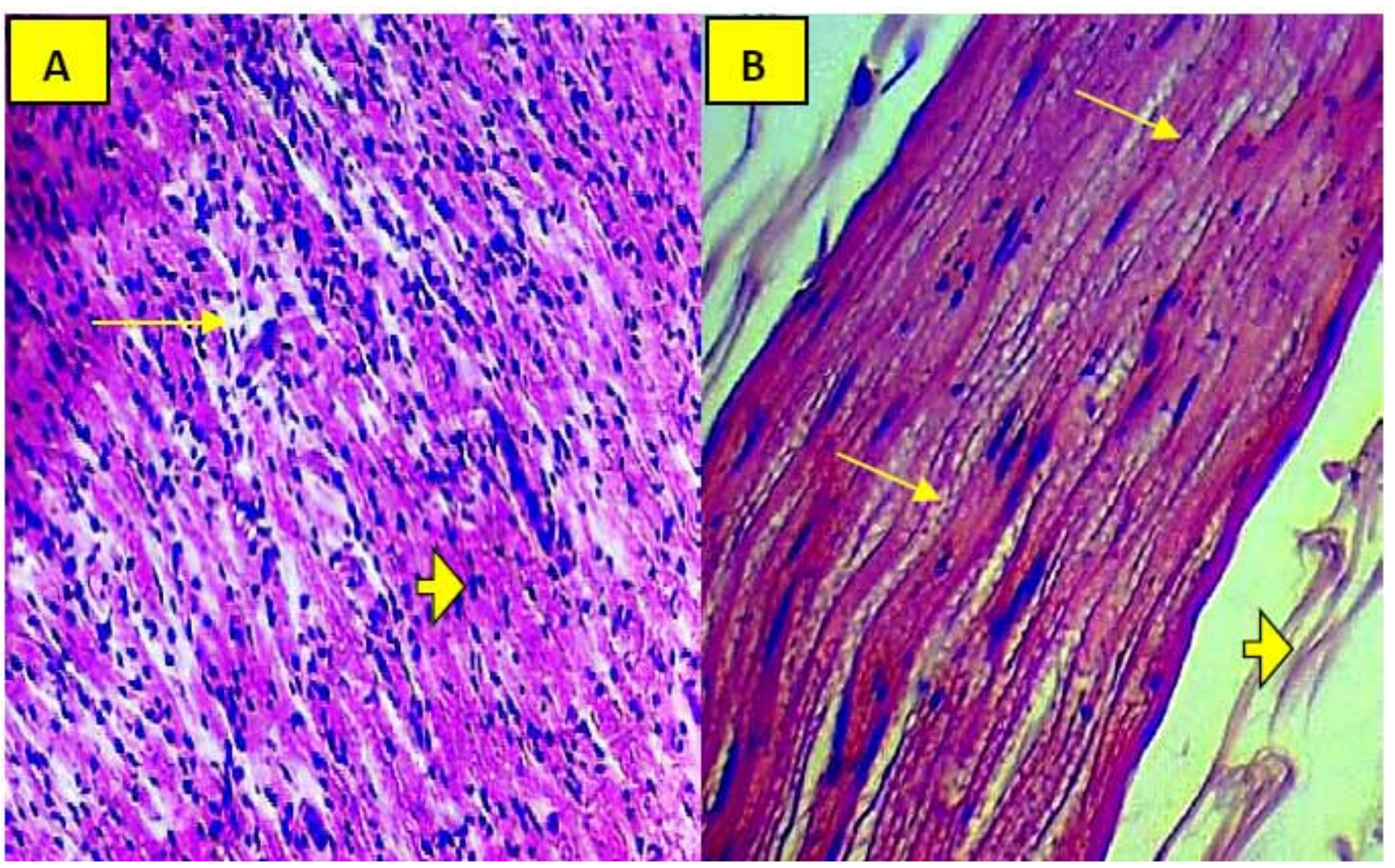

Fig. 2: Longitudinal section of the radial nerve in (SG)at 16th weeks PO. A.middle segmentshows minimum vacuolated degenerated nerve fibers, (thin arrows) with improved myelination and increased number of Schwann cells (arrows head).B. distal segment showsgood remyelination, regeneration of the nerve fibers (thin arrows) and few remnant of conduit (head arrows). H \& E X 20

In combination group (CG), the histopathological examination of the middle segment of the radial nerve $8^{\text {th }}$ weeks PO showed numerous nerve fibers with good angiogenesis and highly basophilic schwann cells (Fig 3A). The distal segment illustrated dark eosinophilic regenerative nerve fibers with extensive proliferative schwann cells, good angiogenesis and fibrous tissue at internal perineurium and no presence of fibrous tissue inside the nerve (Fig 3B).

Histopathological findings of the conduit nerve section in the combination group at 16 weeks PO revealed no to occasional presence of swollen vacuolated degenerate nerve fibers, and no any undulation in the arrangement of the nerve fibers. Increase in number of nerve fibers prominent presence of schwann cells (Fig 4A). The distal segment showed normal parallel orientation of the nerve fibers, a bundle of newly regenerated nerve fibers extended inside the conduits from the proximal stump increased the existence of schwann cells; it was nearly normal section of peripheral nerve (Fig. 4B). 


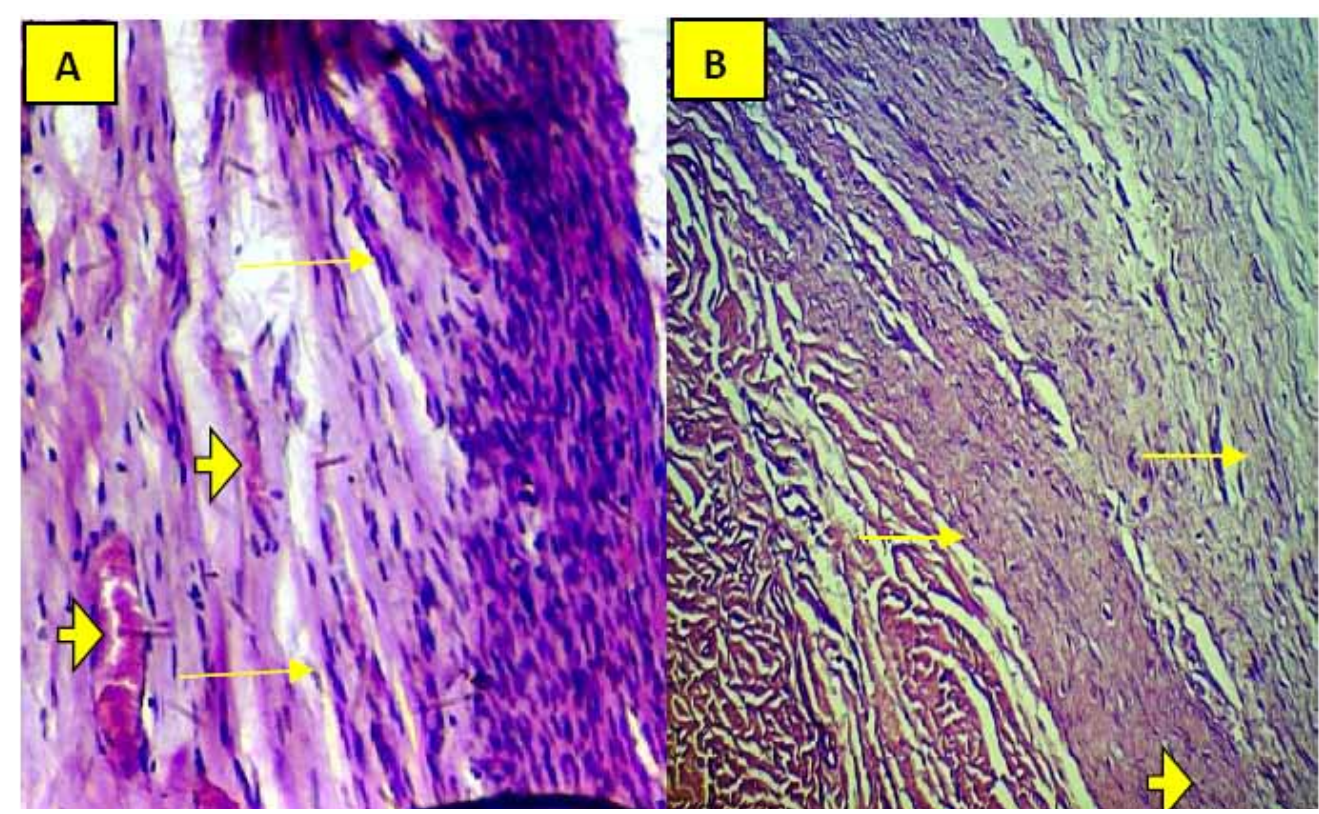

Fig. 3: Longitudinal section of the radial nerve in (CG) at 8th weeks PO. A. middle segment shows good angiogenesis (head arrows) and highly basophilic Schwann cells (thin arrows).B. distal segment shows dark eosinophilic regenerative nerve fibers (thin arrows) with extensive proliferative Schwann cells, and good angiogenesis (head arrows) H \& E X20.

\section{Discussion}

The histopathological outcomes which were obtained by the present study at 8 weeks PO, observed that the variation in the level of nerve regeneration process between the treatment groups may be related to the variation in the cells quantity and quality and due to release a wide range of neurotrophic factors that promote myelin sheath formation, neovascularization and reduced inflammatory reaction that's precipitated in the regeneration process. The increased number of Schwann cells observed on 8th weeks PO in the scaffold group was similar to that observed in the combination group resulting from a high concentration of stem cells in the scaffold. It is reported that scaffold utilized in the present study contains a large number of stromal stem cells ${ }^{(24)}$ which are directly released from this scaffold to the transected peripheral nerve. Effectively, increased angiogenesis, VEGF, FGF and proximity to associated nerve tissue combined to stimulate differentiation of stem cells into Schwann cells. Previous studies confirmed that the Schwann cells release proteases and also work in conjunction with macrophages to phagocytise and remove myelin and axon debris. There is thus a codependence between these two cells as macrophages are mitogenic to Schwann cells and participate with Schwann cells in the provision of trophic (feeding) and tropic (guidance) factors for regenerating axons $(25,26)$. These results were in agreement with $^{(27)}$ were evaluated the use of the decellularized human umbilical artery (hUA) as nerve guidance conduit, the authors showed that decellularized hUAs after implantation were rich in nerve fibers and characterized by improved sciatic functional index (SFI) values and supported elongation and bridging of the $10 \mathrm{~mm}$ nerve gap in rats. The study by ${ }^{(28)}$ implantation of a fetal porcine urinary bladder extracellular matrix (fUB-ECM) in a trigeminal, infra orbital nerve branch transection and direct endto-end repair model in rat, significantly improved epi- and endoneurial organization and increased both neovascularization and growth associated protein-43 (GAP-43) expression at PN repair sites. Scaffolds seeded with HUC-MSCs of which the environment had been conditioned in such a way to obtain the factors supporting nerve regeneration. The results of the present study are in agreement with the results of study of ${ }^{(29)}$ injected UCMSC-derived extracellular vesicles (EVs) into the tail veins of rats and sutured a silicone rubber tube into the sciatic nerve gaps of 24 rats. The authors found that UCMSC-EVs promoted motor function recovery and regeneration of axons and attenuated muscle atrophy at 8 wk. Another study by ${ }^{(30)}$ confirmed that using of BMSCs were then engrafted via UBM-implant as a powder in the hemisected dog spinal cord, showed minimal scar 
tissue formation and proliferation and orientation of regenerative nerve fiber compared to control group at 8 wk. The molecular and cellular mechanisms regulating neovascularization and axon regrowth afer peripheral nerve injury are poorly understood ${ }^{(31,32)}$.However, many studies suggest angiogenesis and neurogenesis are closely linked and likely modulated by the innate immune response to peripheral nerve injury $(33,34)$. Macrophages are hypothesized to respond to and direct endothelial cell migration and the formation of new blood vessels in hypoxic tissues. In turn, newly formed blood vessels have been shown to guide Schwann cells and hence axon regrowth across PN injuries ${ }^{(35,36)}$.

Interestingly, the sections of the proximal segment in combination group at the end of $16^{\text {th }}$ week PO showed the absence of degeneration and vacuolation, increased number of Schwann cells, good orientation and scanty scar tissue in the epineurium of nerve fibers. The mid and distal segments showed remarkable angiogenesis, good orientation and myelination of nerve fibers. This result suggested that employ both biological implants (UBM and HUC) seeded with HUCMSCs synergistically promoted regeneration and improved the functional recovery of radial nerve injury by release a wide range of neurotrophic factors that greater myelin sheath formation in the middle part of the graft, neovascularization and reduced inflammatory reaction. However, the functional (UBM and HUC) may provide good support for the newborn regenerating fibers and guide their growth in the right direction to bridge the nerve gap. As expected, the scaffolds seeded with HUCMSCs combination resulted in better functional recovery compared with the scaffolds alone. This result is consistent with of study of ${ }^{(37)}$ used longitudinally oriented collagen conduit (LOCC) loaded with MSCs after sciatic nerve transection in dogs models we found that the use of an LOCC seeded with MSCs results in the acceleration of sciatic nerve regeneration and the combination resulted in better functional recovery compared with the LOCC alone. In addition, ${ }^{(38)}$ investigated the efficacy of a muscle-stuffed vein seeded with neural trans differentiated human mesenchymal stem cells as an alternative nerve conduit to repair a 15$\mathrm{mm}$ sciatic nerve defect in athymic rats, conclusion that combinations promote peripheral nerve regeneration through the secretion of neurotrophic factors. In contrast, a study by ${ }^{(39)}$ indicate that the small intestine submucosa and poly (caprolactone-co-lactide)-nerve guidance conduit are promote nerve regeneration at $15-\mathrm{mm}$ sciatic nerve defect gap after 16 weeks in rats model. As well as, the results obtainedby a study of ${ }^{(40)}$ reported that the histopathology of sciatic nerve treated with BMSCs showed an increased number of Schwann-like cells. The BMSCs are believed to act as Schwann cells in that they function to prevent neuronal cells death and promote directional axonal growth. As they proliferate to fill endoneurial sheaths, they form longitudinal columns commonly known as bands of Bungner ${ }^{(41)}$. Within days after injury, Schwann cells begin to divide and create a pool of dedifferentiated daughter cells without axon contact. Schwann cells down-regulate their normal proteins such as peripheral myelin protein-22 (PMP22), myelin basic protein (MBP), myelin associated glycoprotein (MAG), P0 and connexin-32 to convert the phenotype of premyelinating cell ${ }^{(42)}$. These dedifferentiated Schwann cells upregulate expression of the nerve growth factor (NGF), neurotrophic factors, cytokines, and other compounds that lead to Schwann cell differentiation and proliferation. The latter are important in preventing neuronal apoptosis in response to injury and potentiate the migration and adhesion of Schwann cells to axonal projections ${ }^{(43)}$.

\section{Conclusions}

The biological implants urinary blabber matrix and human umbilical cord extracellular matrix may have the potential to regenerate radial nerve defect, seeded on HUC-MSCs transplantation being more effective.

Financial Disclosure: There is no financial disclosure.

Conflict of Interest: None to declare.

Ethical Clearance: All experimental protocols were approved under the Department of Surgery and Obstetrics, College of Veterinary Medicine/University of Baghdad and all experiments were carried out in accordance with approved guidelines.

\section{References}

1. Kouyoumdjian J, Graç C, Ferreira VM. Peripheral nerve injuries: A retrospective survey of 1124 cases. Neurol India., 2017;65(3):551.

2. Kouyoumdjian JA. Peripheral nerve injuries: a retrospective survey of 456 cases. Muscle Nerve, 2006;34:785-788.

3. Gaudin R, Knipfer C, Henningsen A. Approaches to peripheral nerve repair: Generations of biomaterial conduits yielding to replacing autologous nerve 
grafts in craniomaxillofacial surgery. Biomed Res. Int., 2016; (13):1-18.

4. Carriel V, Garrido-Gomez J, Hernandez-Cortes P. Combination of fibrin-agarose hydrogels and adipose-derived mesenchymal stem cells for peripheral nerve regeneration. J Neural Eng., 2013;10(2): 026022.

5. Kostereva NV, Wang Y, Fletcher DR, Unadkat JV, Schnider JT, Komatsu C. IGF-1 and chondroitinase $\mathrm{ABC}$ augment nerve regeneration after vascularized composite limb allotransplantation. PLoS One, 2016;11(6).

6. Cui L, Jiang J, Wei L, Zhou X, Fraser J, Snider B, Yu S. Transplantation of embryonic stem cells improves nerve repair and functional recovery after severe sciatic nerve axotomy in rats. Stem Cells, 2008; 26(5):1356-1365.

7. Carr M J, and Johnston A P. Schwann cells as drivers of tissue repair and regeneration. Curr. Opin. Neurobiol.,2017; 47: 52-57.

8. Wang C, Lu C, Peng J, Hu C, Wang Y. Roles of neural stem cells in the repair of peripheral nerve injury. Neural Regen. Res.,2017; 12: 2106-2112.

9. Han J W, Choi D, Lee M Y, Huh Y H, Yoon Y $\mathrm{S}$. Bone marrow-derived mesenchymal stem cells improve diabetic neuropathy by direct modulation of both angiogenesis and myelination in peripheralnerves. Cell Transplant,2016; 25(2): 313-326.

10 Mitsuzawa S,Ikeguchi R, Aoyama T, Takeuchi H, Yurie H, Oda H, Ohta S, Ushimaru M, Ito T, Tanaka M, Kunitomi Y, Tsuji M, Akieda S, Nakayama K, Matsuda S. The efficacy of a scaffold-free Bio 3D conduit developed from autologous dermal fibroblasts on peripheral nerve regeneration in a canine ulnar nerve injury model: a preclinical proof-of-concept study. Cell Transpl., 2019;28(910):1231-1241.

11. Xue C, Zhu H, Tan D, Ren H, Gu X, Zhao Y, Zhang P, Sun Z, Yang Y, Gu J, Gu Y, Gu X. Electrospun silk fibroin-based neural scaffold for bridging a long sciatic nerve gap in dogs. J Tissue Eng Regen Med., 2017;12:1143-1153.

12. Yao Y, Cui Y, Zhao Y, Xiao Z, Li X, Han S. Effect of longitudinally oriented collagen conduit combined with nerve growth factor on nerve regeneration after dog sciatic nerve injury. J Biomed Mater Res B Appl Biomater., 2018;6:2131-2139.
13. Li R, Liu Z, Pan Y, Chen L, Zhang Z, Lu L. Peripheral nerve injuries treatment: a systematic review. Cell BiochemBiophys., 2014;68:449-454.

14. Zhao, X, Cui K, Li Z. The role of biomaterials in stem cell-based regenerative medicine. Future Medicinal Chemistry, 2020; 11 (14).

15. Rbia N, Bulstra LF, SaffariTM, Hovius SE, Shin AY. Collagen Nerve Conduits and Processed Nerve Allografts for the Reconstruction of Digital Nerve Gaps: A Single-Institution Case Series and Review of the Literature. World Neurosurg., 2019; 127: 1176-1184.

16. Kaizawa Y, Kakinoki R, Ikeguchi R. A nerve conduit containing a vascular bundle and implanted with bone marrow stromal cells and decellularized allogenic nerve matrix. Cell Transpl., 2017; 26: 215-228.

17. Li Y, Yu Z, Men Y, Chen X, Wang B. Lamininchitosan-PLGA conduit co-transplanted with Schwann and neural stem cells to repair the injured recurrent laryngeal nerve. Exp. Ther. Med., 2018; 16: $1250-1258$.

18. Zhang Y, Luo H, Zhang Z, Lu Y, Huang X, Yang L, Xu J., Yang W., Fan X, Du B. A nerve graft constructed with xenogeneic acellular nerve matrix and autologous adipose-derived mesenchymal stem cells. Biomaterials, 2010; 31: 5312-5324.

19. Eberli D,Atala A,Yoo JJ. One and four layer acellular bladder matrix for facial tissue reconstruction. J. Mater. Sci. Mater. Med.,2011; 22:741-751.

20. Rosario D J, Reilly G C, Salah E A, Glover M, Bullock A J,Macneil S. Decellularization and sterilization of porcine urinary bladder matrix for tissue engineering in the lower urinary tract. Regen. Med., 2008; 3(2): 145-156.

21. Kočí Z, Výborný K, Dubišová J, Vacková I, Jäger A, Lunov O, Jiráková K, Kubinová Š. Extracellular Matrix Hydrogel Derived from Human Umbilical Cord as a Scaffold for Neural Tissue Repair and Its Comparison with Extracellular Matrix from Porcine Tissues. Tissue Eng Part C., 2017; 23(6):333-345.

22. MennanC, Brown S, McCarthy H, Mavrogonatou E, Kletsas D, Garcia J, Balain B, Richardson J, Roberts S. Mesenchymal stromal cells derived from whole human umbilical cord exhibit similar properties to those derived from Wharton's jelly and bone marrow. FEBS Open Bio.,2016; 6: 10541066. 
23. Freshney R I. Application of Cell Cultures to Toxicology. Cell Biology and Toxicology, 2001; 17(4-5):213-230.

24. Jurga M, Dainiak M B, Sarnowska A, Jablonska A, Lukomska B. The performance of laminincontaining cryogel scaffolds in neural tissue regeneration. Biomaterials,2011; 32(13): 34233434.

25. Lee S K, and Wolfe S W. Peripheral nerve injury and repair. J. Am. Acad. Orthop. Surg., 2000; 8: 243-252.

26. Osborne M C, Verhovshek T, Sengelaub D R. Androgen regulates trkB immunolabeling in spinal motoneurons. J. Neurosci. Res., 2007; 85: 303-309.

27. Gontika I, Katsimpoulas M, Antoniou E, Kostakis A, Stavropoulos-GiokaC., Michalopoulos E. Decellularized Human Umbilical Artery Used as Nerve Conduit. Bioengineering, 2018; 5: 100.

28. Ren T, Faust A, Merwe Y, Xiao B, Johnson S, Kandakatla A, Gorantla V, Badylak S, Washington K,Steketee B. Fetal extracellular matrix nerve wraps locally improve peripheral nerve remodeling after complete transection and direct repair in rat. Scientific Reports, 2018; 8 (1): 4474.

29. Ma Y, Dong L, Zhou D, Li L, Zhang W, Wang $X$. Extracellular vesicles from human umbilical cord mesenchymal stem cells improve nerve regeneration after sciatic nerve transection in rats. Journal of cellular and molecular medicine,2019; 23(4): 2822-2835.

30. AL-Ameri SHA, and Al-Timmemi HAK. The Effectiveness of Extracellular Matrix Derived from Bovine Urinary Bladder Matrix on Spinal Cord Injury in Dog. Indian Journal of Natural Sciences,2018; 9(50): 976 - 997.

31. Fantin A, Vieira J M, Gestri G, Denti L, Ruhrberg C. Tissue macrophages act as cellular chaperones for vascular anastomosis downstream of VEGF-mediated endothelial tip cell induction. Blood, the Journal of the American Society of Hematology,2010; 116(5): 829-840.

32. Bongso A, and Fong C Y. The therapeutic potential, challenges and future clinical directions of stem cells from the Wharton's jelly of the human umbilical cord. Stem Cell Reviews and Reports,2013; 9(2): 226-240.

33. Wang C, Lu CF, Peng J, Hu C, Wang Y. Roles of neural stem cells in the repair of peripheral nerve injury. Neural Regen. Res., 2017; 12: 2106-2112.
34. Mukai T, Tojo A, Nagamura-Inoue T. Umbilical cord-derived mesenchymal stromal cells contribute to neuroprotection in neonatal cortical neurons damaged by oxygen-glucose deprivation. Frontiers in Neurology, 2018; 9: 466-472.

35. Cui B, Li E N, Yang B O, Wang B O. Human umbilical cord blood-derived mesenchymal stem cell transplantation for the treatment of spinal cord injury. Experimental and therapeutic medicine, 2014; 7(5): 1233- 1236.

36. Suzuki K, Tanaka H, Ebara M, Uto K, Yoshikawa H. Electrospun nanofiber sheets incorporating methylcobalamin promote nerve regeneration and functional recovery in a rat sciatic nerve crush injury model. Acta biomaterialia, 2017; 53: 250259.

37. Cui Y., Yao Y, Zhao Y, Xiao Z, Cao Z, Han S, Dai J. Functional collagen conduits combined with human mesenchymal stem cells promote regeneration after sciatic nerve transection in dogs. Journal of Tissue Engineering and Regenerative Medicine,2018; 12(5): 1285-1296.

38. Ramli K, Gasim A I, Ahmad A A, Htwe O, Mohamed Haflah N H,Baharudin A. Efficacy of human cell-seeded muscle-stuffed vein conduit in rat sciatic nerve repair. Tissue Engineering Part A, 2019; 25(19-20): 1438-1455.

39. Shim S W, Kwon DY, Lee B. N, Kwon J S, Park J H, Lee J H, Kim W D. Evaluation of small intestine submucosa and poly (caprolactone-co-lactide) conduits for peripheral nerve regeneration. Tissue Engineering Part A,2015; 21(5-6): 1142-1151.

40. Al-Timmemi H, Ibrahim R,, Karim A, Abz Z, Azmi T. Clinical and histopathological observations of autologous bone marrow stromal cells implantation on the regeneration of sciatic nerve neurotmesis in rabbit. African Journal of Biotechnology, 2012; 10(33): 6310-6318.

41. Scherer SS, and Easter S S. Degenerative and regenerative changes in the trochlear nerve of goldfish. Journal Neurocytology, 1996; 13: 519565.

42. Hall S. Mechanisms of repair after traumatic injury. Journal of Bone Joint Surgery, 2005; 87: 13091319.

43. Boyd JG., and Gordon T. Neurotrophic factors and their receptors in axonal regeneration and functional recovery after peripheral nerve injury. Molecular Neurobiology, 2003; 27: 277-323. 